\title{
A Study on Body Mass Index and Bone Mineral Density among Adult Males
}

\author{
Sentitemsu Ao ${ }^{1}$, Bishu Debbarma ${ }^{1}$, L. Suresh Roy ${ }^{2}$, Deisha Balari Rymbui ${ }^{1}$ \\ ${ }^{I}$ (Post Graduate Student, Department Of Physiology, RIMS, Manipur, India) \\ ${ }^{2}$ (Professor, Department Of Physiology, RIMS, Manipur, India)
}

\begin{abstract}
:
Background:Body mass index (BMI) is defined as the body mass (weight) divided by the square of the body height, and is universally expressed in units of $\mathrm{kg} / \mathrm{m}^{2}$. Bone Mineral Density (BMD) test measures the density of minerals present in the bones. Role of obesity as a risk factor for osteoporosis and its related consequences remains unsettled. This study was conducted to analyze the interplay between body mass index and bone mineral density in men, since most of those studies were conducted on women.

Materials and methods:The study was done on 60 healthy males in the age group of 20years and above. Anthropometric measurement of height $(\mathrm{m})$ and weight $(\mathrm{kg})$ was done. Participants were categorized into three BMI groups according to WHO criterion. BMD of lumbar spine was determined using enCORE-based X-ray bone densitometer (Lunar Prodigy advance, GE Medical Systems, USA) based on DEXA scan. Diagnosis of osteoporosis and osteopenia were done according to WHO T-score criteria. Statistical analysis was done using SPSS software version 21.
\end{abstract}

Results: The result shows that subjects with higher BMI are having high BMD, decreasing the occurrence of osteoporosis. It was also evident that subjects in the higher age group were more prone of having osteoporosis, reflecting low BMD.

Conclusion:From the results it can be concluded that BMI and BMD showed a positive correlation, whereas, advancing age is associated with low BMD.

Keywords: BMI, BMD, Osteoporosis, Osteopenia.

\section{Introduction}

The body mass index (BMI) is defined as the body mass (weight) divided by the square of the body height, and is universally expressed in units of $\mathrm{kg} / \mathrm{m}^{2}$. Based on the value a person can be categorized as underweight, normal weight, overweight, or obese.Obesity is a medical condition in which excess body fat has accumulated to the extent that it may have a negative effect on health. Bone Mineral Density (BMD) test measures the density of minerals present in the bones. Measurement of bone mineral density is an essential tool in the evaluation of patients at risk for osteoporosis, a condition in which the bones become less dense and more likely to break ${ }^{1}$. WHO used astandardized score, called T-score, which compare BMD to average values for young healthy women to define osteoporosis.T-score of -2.5 and below is categorized as osteoporosis ${ }^{2}$.Role of obesity as a risk factor for osteoporosis and its related consequences remains unsettled. Several studieshave reported that body mass index has a positive correlation with BMD, thereby showing a protective role against osteoporosis $^{3-5}$. However, there are some studies that contradict to this data ${ }^{6-8}$. Thisstudy was conducted to analyze the interplay between body mass index and bone mineral density in men, since most of those studies were conducted on women.

\section{Materials And Methods}

The study was a cross sectional study conducted in the department of Physiology and Physical Medicine \& Rehabilitation, RIMS, Manipur, India. The study was done on 60 healthy males in the age group of $20 y r s$ and above. Subjects with history of diseases that might affect bone metabolism or intake of drugs that might influence BMD were excluded from the study. Informed written consent was taken from all the subjects after having explaining them the study protocol. Study met the approval from the Institutional Ethics Committee, RIMS, Imphal. Anthropometric measurement of height (m) and weight ( $\mathrm{kg}$ ) wasdone. Participants were categorized into three BMI groups according to WHO criterion. BMD of lumbar spine was determined using enCORE-based X-ray bone densitometer (Lunar Prodigy advance, GE Medical Systems, USA) based on DEXA scan. Diagnosis of Osteoporosis and Osteopenia were done according to WHO T- score criteria.

\subsection{Data analysis}

Statistical analysis was done using SPSS software version 21. Mean and Standard deviation were assessed. Fisher's Exact and Pearson's Correlation tests was done. 


\section{Results}

Table 1. Demographicprofile of study subjects

\begin{tabular}{|l|l|l|l|l|}
\hline & Total & $\begin{array}{l}\text { Normal } \\
\left(\leq 24.9 \mathrm{Kg} / \mathrm{m}^{2}\right)\end{array}$ & $\begin{array}{l}\text { Overweight } \\
\left(25-29.9 \mathrm{Kg} / \mathrm{m}^{2}\right)\end{array}$ & $\begin{array}{l}\text { Obese } \\
\left(\geq 30 \mathrm{Kg} / \mathrm{m}^{2}\right)\end{array}$ \\
\hline Age $($ Years $)$ & $38.30 \pm 15.81$ & $34.96 \pm 17.08$ & $41.15 \pm 13.90$ & $46.66 \pm 10.91$ \\
\hline BMD $\left(\mathrm{gm} / \mathrm{cm}^{2}\right)$ & $1.09 \pm 0.15$ & $1.04 \pm 0.16$ & $1.14 \pm 0.14$ & $1.16 \pm 0.07$ \\
\hline
\end{tabular}

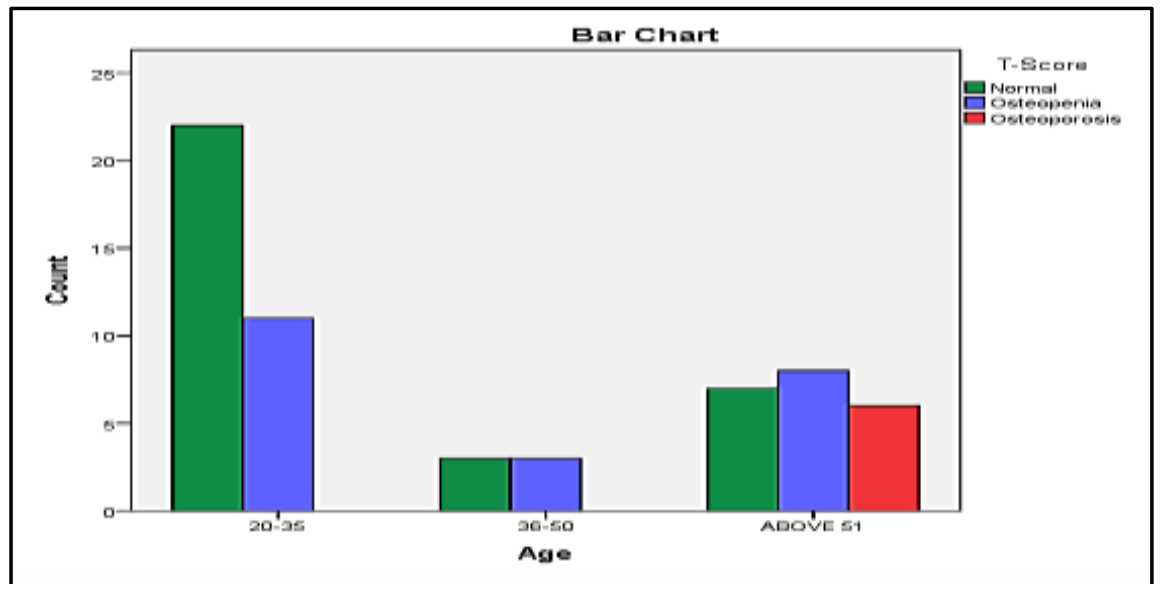

Fig 1. Age with BMD

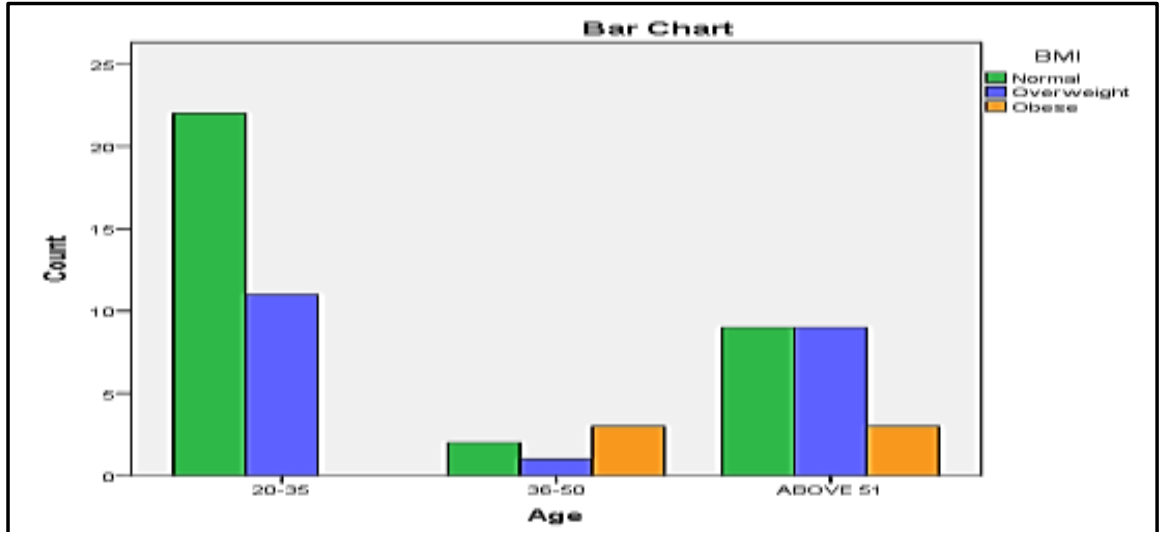

Fig 2. Age with BMI

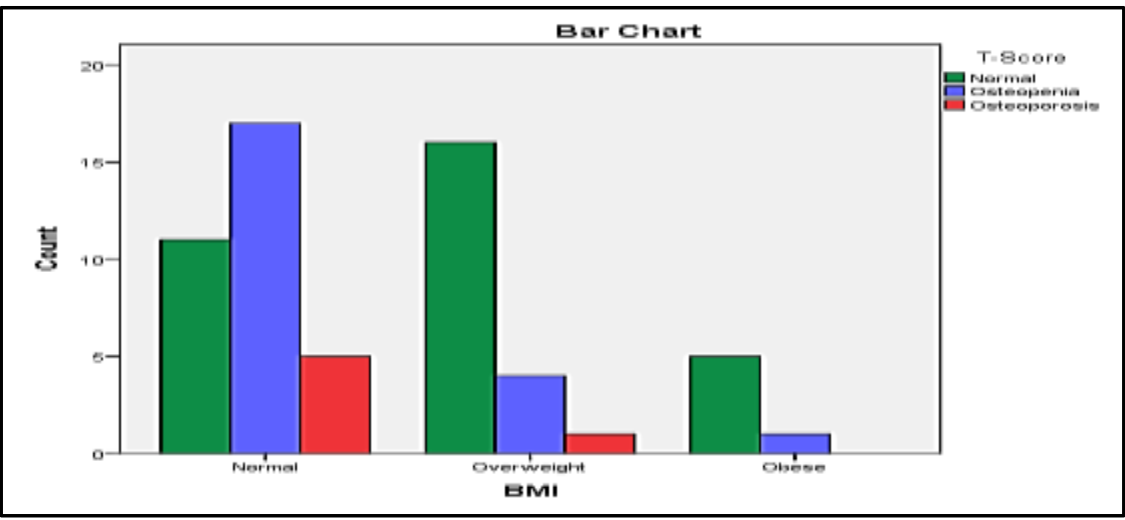

Fig 3. BMI with BMD

Table 2. Pearson's Correlation coefficients

\begin{tabular}{|l|l|l|l|}
\hline & & BMI & BMD \\
\hline \multirow{2}{*}{ Age } & $\mathrm{r}$ & 0.170 & -0.534 \\
\cline { 2 - 4 } & $\mathrm{p}$ & $0.005^{* *}$ & $0.007^{* *}$ \\
\hline \multirow{2}{*}{ BMI } & $\mathrm{r}$ & & 0.424 \\
\cline { 2 - 4 } & $\mathrm{p}$ & & $0.016^{*}$ \\
\hline
\end{tabular}


It was obvious that with increasing BMI, there was decrease in the occurrence of osteoporosis. This shows that subjects with higher BMI are having high BMD (Fig 3). There was a statistically significant association between BMI and BMD $(\mathrm{P}<.05)$. The details are depicted in Table 2. It was also evident that subjects in the higher age group were more prone of having osteoporosis, reflecting low BMD in this age group (Fig 1), and this was statistically significant Table 2 .

\section{Discussion}

From the results it was evident that BMI have a positive correlation with BMD. Lloyd $\mathrm{J}$ et $\mathrm{al}^{9}$ also in his study concluded that there was a significant relationship between BMI and BMD supporting our findings. M.R. Salamatet $\mathrm{al}^{10}$ and A. Baheiraei et $\mathrm{al}^{11}$ also reported this trend of interplay between BMI and BMD.

\section{Some of the explanation that tries to explain this trend of association is:}

- Heavier mechanical loading on bones with subsequent bone remodelation to resist this loading.

- Role of several adipokines in bone remodeling through effect on both formation and resorption.

- Increased secretion of insulin and increased plasma levels of leptin.

- Increasedestrogen synthesis in adipose tissue.

However, a negative association of obesity with BMD was observed in some studies, contradicting this study ${ }^{12,13}$. Assumed mechanisms put forth to support their results were, secretion of pro-inflammatory cytokines that stimulate bone resorption, decreased levels of adiponectins and increased parathormone levels. Theresults also revealed that there was a negative relationship between age and BMD. And there are few studies that documented advancing age was associated with low $\mathrm{BMD}^{14,15}$.

\section{Conclusion}

From the results itcan be concluded that BMI and BMDshow a positive correlation, whereas, advancing age is associated with low BMD. So, early assessment of BMD can be used as a preventive measure against osteoporosis. This may help reduce fractures among ageing male population and its associated morbidity and mortality.

\section{References}

[1]. J.A Kanis, P.Delmas, P Burckhardt, C Cooper, DTorgerson, Guidelines for diagnosis and management of osteoporosis, Osteoporosis Int, 7, 1997, 390-406.

[2]. F.D Shuler, JConjeski, D Kendall, JSalava, Understanding the burden of osteoporosis and use of the World Health Organization FRAX, Orthopedics, 35, 2012, 798-805

[3]. D.T. Felson, Y Zhang, M.T. Hannan, J.JAnderson, Effects of weight and body mass index on bone mineral density in men and women: the Framingham study, Journal of Bone and Mineral Research, 8(5), 1993, 567-573.

[4]. T.V Nguyen, J.R Center, J.A Eisman, Osteoporosis in elderly men and women: effects of dietary calcium, physical activity, and body mass index, Journal of Bone and Mineral Research, 15(2), 2000, 322-331.

[5]. D.J.M. Van Der Voort, S. Brandon, G.J. Dinant, J.W.J. Van Wersch, "Screening for osteoporosis using easily obtainable biometrical data: diagnosticaccuracy of measured, self-reported and recalled BMI, and related costs of bone mineral density measurements," Osteoporosis International, 11(3), 2000, 233-239.

[6]. E.A.Greco, R.Fornari, F. Rossi, V.Santiemma, G.Prossomariti, C.Annoscia, et al, Is obesity protective for osteoporosis? Evaluation of bone mineral density in individuals with high body mass index, Int. J. Clin. Pract, 64, 2010, 817-820.

[7]. K.C. Kim, D.H. Shin, S.Y. Lee, J.A.Im, L.Duk-Chul, Relationbetweenobesityandbonemineraldensity and vertebral fractures in Korean postmenopausal women, Yonsei Med. J, 51, 2010, 857-863.

[8]. J.E. Compston, J.Flahive, D.W.Hosmer, N.B. Watts, E.S.Siris, S. Silverman, et al, Relationship of weight, height, and body mass index with fracture risk at different sites in postmenopausal women: The Global Longitudinal Study of Osteoporosis in Women (GLOW), J. Bone Miner. Res, 29, 2014, 487-49.

[9]. J.T. Lloyd, D.E. Alley, W.G. Hawkes, M.C. Hochberg, S.R. Waldstein, D.L.Orwig, Body mass index is positively associated with bone mineral density in US older adults, Arch Osteoporos, 9(1), 2014, 175.

[10]. M.R. Salamat, A.H. Salamat, I. Abedi, M. Janghorbani, Relationship between weight, body mass index and bone mineral density in men referred for Dual energy X ray absorptiometry scan in Isfahan, Iran, J Osteoporos, 2013, 2059-2063.

[11]. A. Baheiraei, N.A. Pocock, J.A. Eisman, N.D. Nguyen, T. V. Nguyen, "Bone mineral density, body mass index and cigarette smoking among Iranian women: implications for prevention," BMC Musculoskeletal Disorders, 6(34), 2005.

[12]. S. Gonnelli, C.Caffarelli, R. Nuti, Obesity and fracture risk, Clinical Cases in Mineral and Bone metabolism, 11(1), 2014, 9-14.

[13]. S. Moren, J.F. Tsang, W.D. Leslie, Weight and body mass index predict bone mineral density and fractures in women aged 40 to 59 years, 20(3), 2009, 363-370

[14]. G. Jones, T. Nguyen, P. Sambrook, P. J. Kelly, J. A. Eisman, "Progressive loss of bone in the femoral neck in elderly people: longitudinal findings from the Dubbo osteoporosis epidemiology study," British Medical Journal, 309(6956), 1994, 691-695.

[15]. T. V. Nguyen, P. N. Sambrook, J. A. Eisman, "Bone loss, physical activity, and weight change in elderly women: the dubbo osteoporosis epidemiology study,” Journal of Bone and Mineral Research, 13(9), 1998, 1458-1467. 